\title{
Life cycle assessment of behind-the-meter Bitcoin mining at US power plant
}

\author{
Martin Roeck ${ }^{1}\left(\mathbb{0} \cdot\right.$ Thomas Drennen $^{1}$
}

Received: 1 August 2021 / Accepted: 21 January 2022 / Published online: 28 February 2022

(c) The Author(s), under exclusive licence to Springer-Verlag GmbH Germany, part of Springer Nature 2022

\begin{abstract}
Purpose Due to its highly energy-intensive process, Bitcoin has attracted the global attention of climate research and media. At the time of this submission, behind-the-meter Bitcoin mining has gained significant traction; however, not a single environmental impact assessment has been conducted on this type of operation. This study seeks to fill the gap, applying the established Life Cycle Assessment methodology to estimate the environmental footprint of a single case study.

Methods A life cycle assessment methodology of a natural gas power plant mining Bitcoin behind-the-meter in the state of New York following the ISO 14040 guidelines was applied. The functional unit (FU) is defined as the attributed generation capacity of $14 \mathrm{MW}$ over the course of a regular full-calendar year in the attributional model. The FU is scaled to $22 \mathrm{MW}$ and $104 \mathrm{MW}$ in the predictive models to represent planned expansion. The TRACI 2.1 method was applied to characterize the environmental impact. The environmental impact categories considered in this study included global warming, acidification, smog formation, and particulate emissions.

Results and discussion Located in New York State, Greenidge LLC, a natural gas power plant produces an estimated 88,440 metric tons of $\mathrm{CO}_{2}$-eq per year to mine Bitcoin behind-the-meter. Annual emissions would total 656,983 metric tons of $\mathrm{CO}_{2}$-eq if the plant devotes $100 \%$ of its generation to Bitcoin mining. The primary driver of greenhouse gas emissions is the generation of electricity itself, accounting for $~ 79 \%$ of the total emissions. At full capacity, annual emissions are comparable to the annual emissions of 140,000 passenger vehicles or the emissions resulting from the burning of 600 million $\mathrm{lb}$ of coal. Further, additional planned cases could produce an estimated 1.9 million tons $\mathrm{tCO}_{2}$-eq per annum.

Conclusions Behind-the-meter Bitcoin mining makes the power plant a significant contributor to global warming at a time when New York State is attempting to radically reduce its greenhouse gas emissions by $85 \%$ by 2050 and to have $100 \%$ carbon-free electricity by 2040 . The environmental impact of this business model is not limited to individual sites but is spread out over upstream impacts as well. In combination, we see that behind-the-meter Bitcoin mining not only goes against local climate initiatives but also poses a significant danger to national initiatives due to feasible scalability, caused by an availability of existing infrastructure and favorable financials.
\end{abstract}

Keywords Energy $\cdot$ Power plant $\cdot$ Climate regulation $\cdot$ Bitcoin $\cdot$ Blockchain $\cdot$ Proof of work

\section{Introduction}

In 2019, global temperatures were the second hottest since the inception of modern recordkeeping (NASA 2019). The associated trend has not gone unnoticed by global

\section{Communicated by Yi Yang.}

Martin Roeck

martineroeck@gmail.com

1 Department of Economics, Hobart and William Smith Colleges, 300 Pulteney St, Geneva, NY, USA policy makers. For example, the 2015 Paris Agreement indicates a consensus of the importance of mitigating GHG and global warming. Unfortunately, global temperatures have already increased by $1.07{ }^{\circ} \mathrm{C}(0.8-1.3$; likely range $)$ since $1850-1900$, closing in on the critical $1.5^{\circ} \mathrm{C}$ mark (IPCC 2021). Further global emissions must be limited to $300 \mathrm{GtCO}_{2}$ (at a $83 \%$ success rate) to stay under the $1.5^{\circ} \mathrm{C}$ target or $900 \mathrm{GtCO}_{2}$ (at a $83 \%$ success rate) to stay under the $2{ }^{\circ} \mathrm{C}$ target (IPCC 2021).

The US policy response to climate change has been inconsistent, illustrated by the withdrawal from the Paris Agreement under the Trump Administration and subsequent 
re-entry in the early days of the Biden Administration. At the same time, US emissions decreased significantly in $2020(-13 \%)$ due to demand shifts during the height of the COVID-19 pandemic (Liu et al. 2020). On the supply-side emissions in the USA are falling due to a transition towards natural gas (Feng et al. 2015). Recent technological advances, including innovations in hydraulic fracturing technology, have made natural gas a favorable financial choice for US power producers (Feng et al. 2015; Belova 2020; Plumer, 2019). The result has been a shift towards natural gas generation, as demonstrated by Greenidge Generation LLC, the subject of this report (Fichman 2011; Balasta 2016). However, as Feng et al. (2015) indicate, both a decrease in energy intensity and a permanent decarbonization, described as a shift from fossil fuels towards renewables or nuclear energy, is necessary to limit the negative impact of climate change in the long-term (Feng et al. 2015). Unfortunately, financial incentives have led some plants, such as Greenidge, to shift a significant portion of its generation capacity into a new energy-intensive sector - Bitcoin mining (Greenidge Generation LLC 2020) — increasing US emissions.

Blockchain technology has been heralded as the future of a cashless society. Primarily associated with cryptocurrencies, blockchain technology has many other potential applications, ranging from healthcare and infrastructure to the financial sector (Mackey et al. 2019; Sun et al. 2016; Chang et al. 2020). Bitcoin, which uses blockchain as its backbone, utilizes a cryptographic algorithm to maintain the anonymity of network transactions (Frankenfield 2020). Computers in the network "mine" for a specified block reward which holds monetary value. The resulting process is highly energy intensive, attracting the global attention of climate research and media (Shane 2017; Mooney et al. 2018; Bloomberg 2017). Various studies have estimated the total annual energy use associated with this mining activity; a recent study summarizing 21 papers on the topic estimates global electricity demand of roughly $<1-6$ GW (Lei et al. 2021) in 2018. Several of the papers referenced in this study estimate associated emissions for the same year: 29 megatonnes $(\mathrm{Mt}) \mathrm{CO}_{2}$-eq (Köhler et al., 2019), 22.0 to $22.9 \mathrm{MtCO}_{2}$ (Stoll et al. 2019), and $63 \mathrm{MtCO}_{2}$ (McCook 2018). For the same year, the maximum estimate by the less rigorous Digiconomist was $73.12 \mathrm{TWh} / \mathrm{yr}$ or $34.73 \mathrm{MtCO}_{2}$-eq (Digicomist, 2020). However, estimates have steadily trended upward from this point (Lei et al. 2021), as high-demand and favorable pricing has exponentially escalated the Bitcoin hash rate since 2017. As of October 2021, the Cambridge Center for Alternative Finance estimated energy demand of $\sim 12$ GW (Cambridge Center for Alternative Finance 2021). A recent estimate of global emissions placed the value at 90.2 $\mathrm{MtCO}_{2}$ (Vries 2021). Mora et al. (November, 2018) notably relate findings back to the Paris Agreement, recognizing that Bitcoin's emissions alone could drive our planet past the $2{ }^{\circ} \mathrm{C}$ mark. ${ }^{1}$

Previous studies of Bitcoin's carbon footprint predominantly consist of bottom-up analysis of global emissions. For example, past modeling approaches explore the composition of mining equipment (Köhler et al. 2019; Stoll et al. 2019; Cambridge Center for Alternative Finance 2021), the geographical distribution of miners (Köhler et al. 2019; Stoll et al. 2019; Digicomist 2020), and the composition of electricity sources (Köhler et al. 2019; Stoll et al. 2019). Köhler et al. (2019) summarize the associated vulnerabilities, describing the explicit uncertainty within previous research (Köhler et al. 2019). The same study applies the Life Cycle Assessment (LCA) methodology, based on a "transparent, valid, and replicable" framework (Köhler et al. 2019). LCAs assess the environmental impact of a product or process by estimating the impact of all stages within a product's lifecycle. Assessments can be utilized in a variety of ways, creating a useful environment not only for global but localized analysis. For instance, studies have been conducted on waste treatment systems (Franklin Associates 2017; Zhao et al. 2009), taxis produced by a single company ( $\mathrm{Li}$ et al. 2016), a combined cycle power and iron plant ( $\mathrm{Li}$ et al. 2017), and a small hydropower plant (Pang et al. 2015). As this form of analysis is aimed at individual optimization and public policy it can also be applied to Bitcoin mining operations at Greenidge Power Plant.

As of 2020 Greenidge has almost 7000 mining servers utilizing $14 \mathrm{MW}$ of "behind-the-meter" electricity capacity (Greenidge Generation LLC 2020). The combined installation represents a $\$ 65$ million investment by parent-firm Atlas Holdings (Greenidge Generation LLC 2020). This includes a 4.6-mile connection between the Empire Gas Pipeline and the facility (Greenidge Generation LLC 2020). The Empire Pipeline connects the Marcellus Shale region to local distribution companies and end users like Greenidge (National Fuel 2020). Locating the data center at the plant ("behind the meter") eliminates distribution costs and minimizes efficiency losses associated with grid networks. By mining Bitcoin, the plant remains lucrative outside of peak load and pricing periods. Plant representatives claim that this difference can amount to as much as $\$ 180 / \mathrm{MWh}, 10$ times the revenue earned without mining Bitcoin (Anzalone 2020). Further, Greenidge has the theoretical ability to expand its mining capability up to $104 \mathrm{MW}$, the total capacity of the plant (Greenidge Generation LLC 2020).

This study seeks to establish the environmental footprint of Bitcoin mining at a single power plant, Greenidge Generation LLC, to create a foundation for further research and

\footnotetext{
1 The authors note that Mora et al. have received several critical responses; consequently, this statement should be taken with caution.
} 
policy. Our LCA utilizes a diverse set of data sources and case specific factors to best estimate potential emissions. We also utilize both current and scaled models to predict future impacts. This establishes a framework for analysis of similar institutions, including data centers, power plants, or Bitcoin operations.

Regionally, New York's Climate Leadership and Community Protection Act (CLCPA) requirements and goals include limiting GHG to $40 \%$ of 1990 levels by 2030 and $80 \%$ by 2050 (NY Department of Environmental Conservation 2020). As such, allowing for economic frameworks that incentivize the continuation of fossil-fuel use must be immediately addressed by research and policy before irreparable damage is committed. In summary, the value of this analysis lies in its individualized scope but widely applicable methodology and results.

\section{Methods}

In this section we follow a framework for individualized analysis using three standardized steps: (1) goal and scope definition, (2) inventory analysis, and (3) the impact assessment phase as defined by ISO 14040 standards. This framework includes a list of case specific factors, sources of viable data, and a standardized impact assessment tool. The framework can be modeled using a variety of applications including open-source and freely available programs such as OpenLCA (OpenLCA 2020) and Brightway2 (Mutel 2020). In this specific case, we use OpenLCA to model both an attributional and predictive approach for analysis. The attributional, or current, model estimates the environmental impact of Bitcoin mining at Greenidge Power Plant using $14 \mathrm{MW}$ of dedicated generation capacity. The predictive model estimates the environmental impact of the mining center once capacity is ramped up to $22 \mathrm{MW}$ and $104 \mathrm{MW}$, respectively. News sources and a press release by Greenidge have indicated that this expansion is planned and thereby represents a business-as-usual scenario (Greenidge Generation LLC 2020; Anzalone 2020).

\subsection{The scope}

In this LCA we produce a best-estimate case study of the Greenidge Power Plant in Dresden, NY. In doing so, we compile and evaluate the environmental consequences of a new business strategy: behind-the-meter Bitcoin production. This requires strict definitions of both the functional reference unit and the product system.

The functional unit of reference (FU), also known as the "product" in question, is defined as the attributed generation capacity of $14 \mathrm{MW}$ over the course of a regular full-calendar year. To account for maintenance and other outages, a load factor of $90 \%$ was used. We use the resulting reference unit, $110,376 \mathrm{MWh}$, to create the attributional model. To create the predictive model, the functional unit is scaled upward to represent $22 \mathrm{MW}$ and $104 \mathrm{MW}$, producing functional units of $173,448 \mathrm{MWh}$ and $819,936 \mathrm{MWh}$, respectively. The motivation behind this choice lies in the scalability and certainty of the measurement. Other units, such as the produced number or value of Bitcoins, are dependent on fluctuating values including price and computing power in the Bitcoin network. This would create a highly uncertain environment that is completely avoided by our reference unit. In addition, the functional unit is easily scaled to represent other power plants and behind-the-meter mining centers.

The product system is a map of consecutive and/or interconnected processes that represent a product's lifecycle. In this case study, the system represents all processes associated with the mining activities at Greenidge Power Plant. As a previous study has indicated that the end-of-life of mining equipment has a minimal effect (Köhler et al. 2019), the lifecycle boundary is limited to the production and use phases (Fig. 1). The production phase includes the extraction and refining of the fuel source, the production of mining equipment, and the transportation of resources. The use phase includes the generation of electricity and operation of mining equipment. The depth of the product system is limited to the inputs required directly for the generation of electricity, the production of mining units, and the operation of the mining units. The impacts of rare-earth metal mining, which are required for the mining units, were not included in the product system. This is also known as cut-off criteria. Without cut-off criteria, system loops are established within the product system. Consider the extraction of a fossil fuel. The process requires electricity, which in return requires the extraction of the fuel. This creates a circular relationship. Cut-offs allow us to estimate the impact of a product without having to model $100 \%$ of the product system. Without cutoffs the estimated impacts of the model would increase, a trade-off that we accept in our analysis.

\subsection{Inventory analysis}

A Life Cycle Inventory (LCI) is a simple inventory of all pathways associated with the product lifecycle. Data collection begins with a description of all activities under analysis. Adequate processes are chosen and should include location, time frame, and case specific factors. In our analysis, we chose pathways that are readily available in public databases. This eliminates the need to quantify each output and input which is typically a resource-intensive component of lifecycle analyses. However, it also increases uncertainty since emissions factors are not obtained directly from the power plant in question. To address this uncertainty, we utilize four 


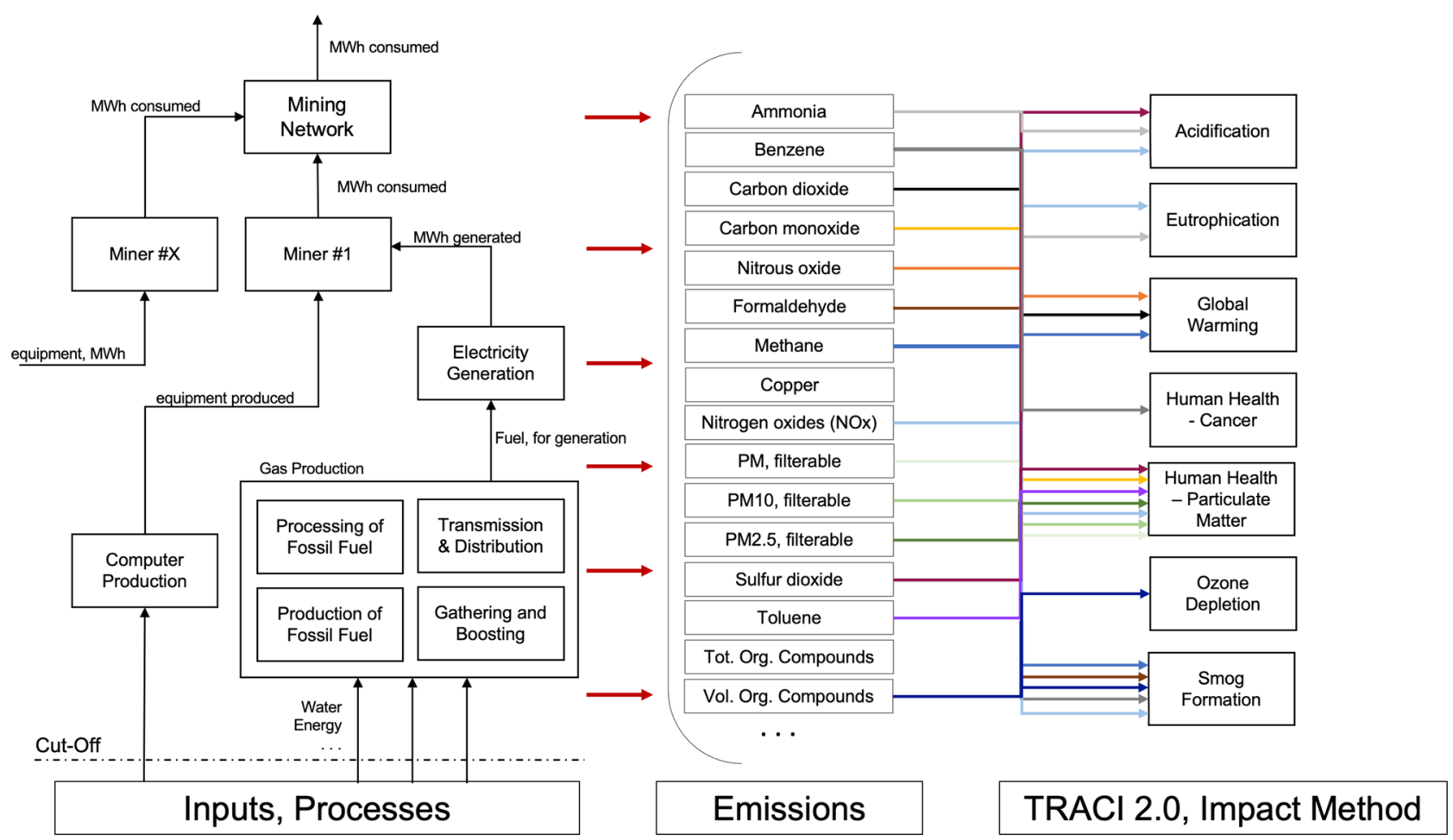

Fig. 1 The structure of the product system. Processes within the product system produce emissions. These emissions affect variety of categories representing the environmental impact of the LCA. Only a subset of the emission paths is shown in order to improve readability

scenarios, representing a variance in case specific factors as well as data sources.

Five case-specific factors were used in this analysis: (1) the method of generation, (2) the fuel source, (3) the heat rate, (4) the type of mining equipment, and (5) control equipment. In our case Greenidge is a shale-fed NG co-generation plant, capable of co-firing up to $19 \%$ of biomass (NYSDEC 2018; NYSDEC 2019). However, EPA data indicates that Greenidge exclusively uses natural gas (EPA 2020). While factors (1-3) are varied across scenarios, the type of mining equipment was held constant. A combination of visual and data analysis indicates that Greenidge uses S17 Pro Mining supplied by Bitmain. This is further supported by the presence of two Bitmain "Ant Boxes" (Redman 2020). The computer production process was scaled using this unit.

\subsection{Data sources and scenarios}

Our model uses the US Life Cycle Inventory Repository (USLCI) from NREL (Federal LCA Commons 2020). This database includes the processes necessary to complete the product system. The gas production process was developed by Littlefield et al. (2019) as part of a life cycle analysis of natural gas extraction and power generation. The computer production process was developed as part of the US Environmentally-Extended Input-Output (USEEIO) model (Yang et al. 2017).

The first scenario, EPA-Ave, assumes the plant uses natural gas produced from the Appalachian basin and operates at the average heat rate for natural gas plants $(7916 \mathrm{Btu} / \mathrm{kWh}$ (EPA 2021) in the USA. The electricity generation process for this scenario was built using the EPA WebFire database (EPA 2020). The second scenario, NREL-32\% (NL-32\%), assumes identical generation and computer production processes and gas production process, but utilizes an alternate electricity generation process, obtained from NREL (Franklin Associates 2003). This process was based on an estimated heat rate of $10,732 \mathrm{Btu} / \mathrm{kWh}$ (efficiency $32 \%$ ). The third scenario (EPA-32\%) uses the EPA database but matches the heat rate of NL-32\%. All other processes of the scenarios, including the source of natural gas and computer equipment, remain identical to NL-32\%. This enables a direct comparison of the NREL and EPA-based generation processes.

Greenidge operates at a higher heat rate $(11,524 \mathrm{Btu} / \mathrm{kWh}$ (EPA 2020)) than more modern plants. To address this difference, the generation process for the fourth scenario, EPAGreenidge (EPA-G), represents a plant with a heat rate of $11,525 \mathrm{Btu} / \mathrm{kWh}$. Table 1 summarizes the four scenarios. 
Table 1 Scenario overview

\begin{tabular}{lllll}
\hline Scenario & EPA-Ave & NL-32\% & EPA-32\% & EPA-G \\
\hline Generation process & EPA & NREL & EPA & EPA \\
Extraction technology & Shale & Shale & Shale & Shale \\
Heat rate $(\mathrm{Btu} / \mathrm{kWh})$ & 7916 & 10,732 & 10,732 & 11,525 \\
Generation, $\mathrm{EF}\left(\mathrm{kg} \mathrm{CO} \mathrm{Cq}_{2} \mathrm{eq} / \mathrm{kWh}\right)$ & 0.44 & 0.59 & 0.58 & 0.63 \\
Gas production, $\mathrm{EF}\left(\mathrm{kg} \mathrm{CO}_{2} \mathrm{eq} / \mathrm{kWh}\right)$ & 0.12 & 0.16 & 0.16 & 0.17 \\
\hline
\end{tabular}

\subsection{Impact assessment phase}

The impact assessment phase describes the environmental consequences of the activity being studied. This is achieved by translating emissions into impact categories. Findings were analyzed using TRACI 2.0, a cohesive impact assessment tool published by the EPA (Bare 2011). This tool summarizes environmental impacts across nine different categories: global warming potential, acidification, smog formation, ozone depletion, $\mathrm{PM}_{2.5}$ and eutrophication, freshwater eco-toxicity, human-health cancer, and human-health non-cancer. TRACI 2.1 was chosen as it is published by a respected entity (EPA), is transparent, is openly available, and is standardized.

\subsection{Predictive model}

Greenidge LLC has plans to expand its current operations to 22-25 MW and eventually to its total capacity of 104 MW (Anzalone 2020). To analyze these scenarios our life cycle was scaled to functional units of $22 \mathrm{MW}$ and $104 \mathrm{MW}$ (173 GWh and $820 \mathrm{GWh}$ at $90 \%$ load factor, respectively).

\subsection{Consequential model}

Due to the favorable financials, similar fossil fuel power plants are transitioning to mining. As of 2021, Hardin Generating Station, a $100+$ MW coal-fired power plant in Big Horn, Montana, is planning to convert to Bitcoin mining (Spegele et al. 2020). Similarly, Digihost, a crypto-currency miner, is working to acquire a natural gas power plant in Niagara County, NY (McKenzie 2021). Greenidge itself plans to expand to half a GW of mining capacity by 2025 according to a recent merger announcement (Greenidge LLC 2021).

To analyze the impact of these planned operations, we adapt the methodology to four new case studies, including the proposed Digihost project in NY, the Hardin coal-fired plant in MT, and two fictional plants in Texas (Table 2). The resulting scenarios are fundamentally different from the attributional case as we vary three of the five casespecific factors used in the analysis: (1) the method of generation, (2) the fuel source, (3) the heat rate, (4) the type of mining equipment, and (5) control equipment. We take control equipment into consideration; however, none of the sites have carbon-capture implemented (EIA 2021). Heat rates were obtained using plant-level data (EIA 2021). Due to a lack of information on mining equipment, the mining equipment was kept identical to the attributional model of Greenidge.

The two fictional cases in Texas were included as Greenidge has indicated that expansion into this region is planned (Greenidge Generation LLC 2021). As specific details are unknown, we modeled an old steam turbine in addition to a high-efficiency Combined-Cycle Gas Turbine. The heat rate for the steam turbine is based on Greenidge, while the heat rate for the CCGT is based on the Digihost power plant. The nameplate capacity for these cases was chosen based on the size of Greenidge as well as the indicated growth pipeline in the region.

\subsubsection{Functional unit in the consequential model}

The functional unit of reference (FU) is defined as the attributed generation capacity of each scenario over the course of a regular full-calendar year. A lower load factor was utilized
Table 2 Consequential scenarios

\begin{tabular}{lllll}
\hline & Digihost & Hardin & Fictional, steam & Fictional, CCGT \\
\hline Method of generation & CCGT & Conventional steam & Steam turbine & CCGT \\
Fuel source & NG - Appalachian & Coal & NG - Gulf Coast & NG - Gulf Coast \\
Heat rate & 7743 & 12,468 & 11,524 & 7743 \\
Mining equipment & Bitmain & Bitmain & Bitmain & Bitmain \\
Carbon-capture & No & No & No & No \\
Location & Niagara County, NY & Bighorn, MT & TX & TX \\
Nameplate capacity & 65.7 & 115.7 & 100 & 100 \\
Load factor & $90 \%$ & $85 \%$ & $90 \%$ & $90 \%$ \\
\hline
\end{tabular}


for the coal scenario (85\%), to account for additional maintenance and outages. The rounded FUs are Digihost $=518$ $\mathrm{GWh}$; Hardin $=862 \mathrm{GWh}$; fictional, steam $=788 \mathrm{GWh}$; and fictional, CCGT $=788 \mathrm{GWh}$.

\section{Results and discussion}

We have limited our results to focus on four key metrics of environmental degradation: global warming, acidification, smog formation, and particulate emissions (Figure 2). All four scenarios return values within the same order of magnitude. Values were calculated for the remaining categories; however, they are not included as they are either limited by emissions controls, not of great enough magnitude, or a distraction to the focus on emissions and air pollution.

\subsection{Greenhouse gas emissions}

In the attributional model we estimate an emission rate of 0.801 metric tons (t) $\mathrm{CO}_{2}$-eq per $\mathrm{MWh}$, which translates into annual emissions of $88,440 \mathrm{tCO}_{2}$-eq annually attributed to

\section{$\mathrm{kg} \mathrm{CO}_{2}$ eq Global Warming}

1.20E+08

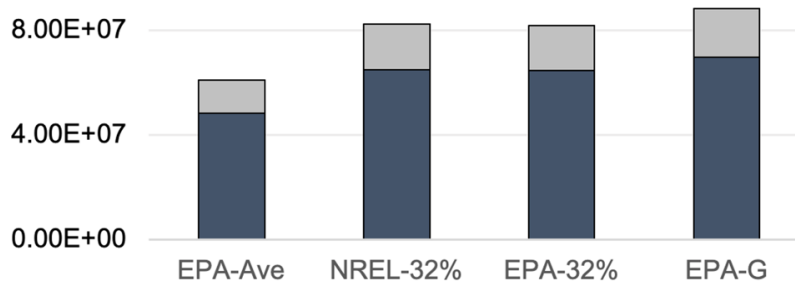

$\mathrm{kg} \mathrm{SO} \mathrm{Seq}$

Acidification

2.25E+05

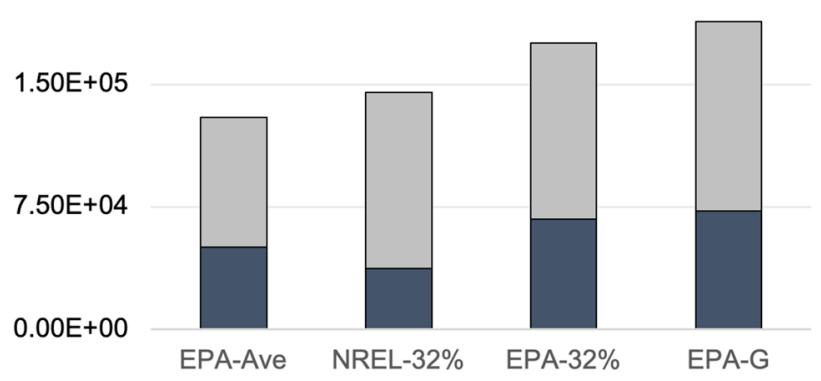

the use of $14 \mathrm{MW}$ of its capacity for mining of Bitcoin at Greenidge. This estimate is significantly higher than other studies of Bitcoin mining, largely because Greenidge relies solely on inefficient natural gas generation, whereas other studies assume that some proportion of electricity use is from less carbon-intensive sources. Specifically, other studies estimate emissions of $0.553 \mathrm{tCO}_{2}$-eq/MWh (Köhler et al. 2019),

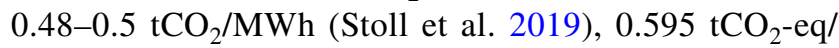
MWh (McCook 2018), and $0.475 \mathrm{tCO}_{2} / \mathrm{MWh}$ (Digicomist, 2020). Köhler and Pizzol (2019) calculate the distribution of miners by region and then use the electricity mix for each. The Sichuan Province in China, the primary source of miners in the Köhler and Pizzol study, has an electricity mix of $80.02 \%$ hydro, $19.42 \%$ coal, $0.53 \%$ natural gas, and $<0.5 \%$ other renewables (Köhler, et al. 2019). Stoll et al. (2019) use a similar method, mapping the IP addresses and pools of miners to countries, resulting in a mix of Asian, European, and North American electricity mixes (Stoll et al. 2019). Digiconomist takes a more elementary approach, assuming that $70 \%$ of miners are located in Chinese grid (per Digiconomist: around $0.7 \mathrm{~kg} \mathrm{CO}_{2}$-eq $/ \mathrm{kWh}$ ) with the remainder being entirely carbon-free (Digicomist 2020). In each case, electricity is partially sourced from renewable energies that have lower impacts than natural gas generation.
PM 2.5 eq

$6.00 \mathrm{E}+03$

$4.00 \mathrm{E}+03$

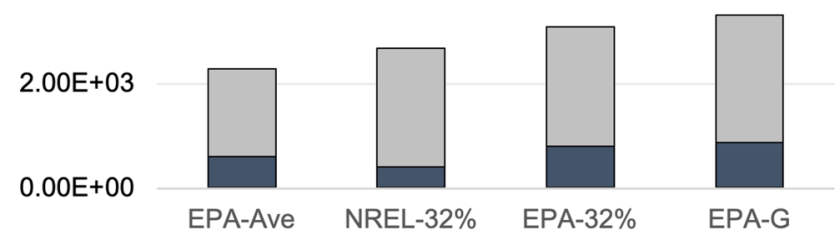

$\mathrm{kg} \mathrm{O3} \mathrm{eq} \mathrm{Smog} \mathrm{Formation}$

$7.50 \mathrm{E}+06$

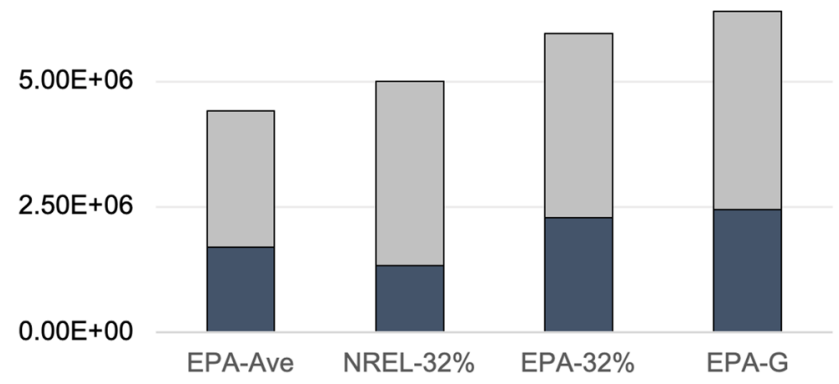

nOther घElec. Generation $\quad$ 口Fuel Production

Fig. 2 Selected results of LCA for the attributional case (FU=110,376 MWh or $14 \mathrm{MW})$ 


\subsection{Process contributions: climate change}

Life-cycle analysis allows for in-depth analysis of emission contributions (Fig. 2). The generation of electricity is the predominant source of emissions, accounting for $79 \%$ of the total $\left(37,223\right.$ to $72,481 \mathrm{t} \mathrm{CO}_{2}$-eq annually). The production phase contributes a significant amount of $\mathrm{CO}_{2}$ under all four scenarios $(21 \%)$. This phase consists of the production, gathering and boosting, processing, transmission, and distribution of fuel (Littlefield et al. 2019). Production covers the construction of the natural gas wells (Littlefield et al. 2019). This stage also includes emissions caused by vented and/or flared gas (Littlefield et al. 2019). The transmission and distribution includes the delivery of natural gas to its end-use location. For reference, a report published by the EPA (2020) stated that pipelines contribute $2.6 \%$ of emissions in the transportation sector (EPA 2020). This is equivalent to 174.9 million $\mathrm{t} \mathrm{CO}_{2}$-eq annually in the USA (EPA 2020). The production of mining equipment adds $\leq 1 \%$ to total emissions. These findings closely match Köhler and Pizzol (2019) estimate of $0.932 \%$ for equipment production.

\subsection{Scenario analysis}

The emissions factors obtained from the EPA WebFire database yield values at the low- and high-end of the "Global Warming" spectrum. This difference arises from the varied power plant efficiencies we use in our scenarios. In 2018 the average natural gas plant in the USA had a heat rate of 7,916 $\mathrm{Btu} / \mathrm{kWh}$ (EPA 2021). That is, the average plant converted $43.1 \%$ of the energy contained in fuel to electricity. Newer technologies have allowed for generators to reach efficiencies of up to 60\%, such as GE's 7HA.01/02 (GE 2015). In comparison, Greenidge has a historical yield of $29.6 \%$, half the rate of newer systems. Since the actual facility was built in 1937 and the current steam turbine was built in 1953 this drastic inefficiency is unsurprising (Greenidge LLC 2020).

In the attributional model, we modeled a single source of natural gas. Previous studies have examined the difference of conventional and shale gas using life-cycle analysis. For example, Jiang et al. (2011) use an economic input-output model to estimate that the Marcellus Shale yields emissions $3 \%$ higher than average domestic gas. Similarly, Stephenson et. al (2011) established an emission intensity $1.8-2.4 \%$ higher for shale gas, when compared to conventional gas in the same year, primarily attributed to higher methane releases during well completion.

\subsection{Smog formation and particulate matter}

The average of all scenarios estimates smog emissions of $6.4 \times 10^{6} \mathrm{~kg} \mathrm{O}_{3}$-eq and particulate matter emissions of
$3.32 \times 10^{3} \mathrm{PM}_{2.5}$-eq before control equipment is taken into consideration. It is difficult to quantify the impact of particulate emissions due to their geographical distribution. A 2008 public health study by the New York Center for Environmental Health used meteorological and statistical analysis of Greenidge to examine the effect on local communities. The study demonstrates no statistical difference in acute respiratory infections when compared to similar regions in upstate New York (NYS Department of Health 2008). The report also notes that Greenidge has significant control equipment in place. These controls include a circulating dry scrubber, a single bed selective catalytic reduction (SCR) system, a selective non-catalytic reduction (SNCR) system, and a basic electrostatic precipitator or baghouse (NYS Department of Health 2008). In combination, these systems significantly limit (>90\%) $\mathrm{NO}_{x}, \mathrm{SO}_{2}$, particulate matter, and other chemical emissions (NYS Department of Health 2008). Information on these systems should be included in analysis when possible. The findings also showed that the extraction and processing of natural gas has the greatest impact in the $\mathrm{PM}_{2.5}$ category (Table 3). This limits the insight offered by the health consultation, which only focused on air pollution directly produced by Greenidge.

Ozone located in the stratosphere plays an important role by blocking UV light that is harmful to biological life on earth. However, when located at lower elevations, ozone can lead to significant health issues. Ozone is not directly emitted by any of the processes in our product system. Instead, it results from nitrogen oxides and volatile organic compounds (VOCs) that are altered through natural photochemical processes (EPA 2021). This LCA shows that these compounds are primarily released during the generation of electricity and extraction of natural gas (Table 2). Previous studies have established a link

Table 3 Process contributions for the human health and smog categories as a percentage of total emissions in each category

\begin{tabular}{llll}
\hline \multicolumn{3}{l}{ Human health $\left(\mathrm{PM}_{2.5}\right.$ eq $)$} & \\
\hline Scenario & Other & Electricity generation & NG, production \\
\hline EPA-Ave & $<1 \%$ & $26 \%$ & $73 \%$ \\
NL-32\% & $<1 \%$ & $15 \%$ & $85 \%$ \\
EPA-32\% & $<1 \%$ & $26 \%$ & $74 \%$ \\
EPA-G & $<1 \%$ & $26 \%$ & $74 \%$ \\
Ave & $<\mathbf{1 \%}$ & $\mathbf{2 3} \%$ & $\mathbf{7 6 \%}$ \\
Smog $\left(\mathrm{kg} \mathrm{O}_{3}\right.$-eq) & & \\
Scenario & Other & Electricity generation & $\mathrm{NG}$, production \\
EPA-Ave & $<1 \%$ & $38 \%$ & $61 \%$ \\
NL-32\% & $<1 \%$ & $26 \%$ & $74 \%$ \\
EPA-32\% & $<1 \%$ & $38 \%$ & $62 \%$ \\
EPA-G & $<1 \%$ & $38 \%$ & $62 \%$ \\
Ave & $<\mathbf{1 \%}$ & $\mathbf{3 5 \%}$ & $\mathbf{6 5 \%}$ \\
\hline
\end{tabular}


Fig. 3 Emission estimates of attributional and predictive cases. Emissions estimates for coal, homes, and vehicles were obtained from the EPA Carbon Equivalencies Calculator (EPA 2020)

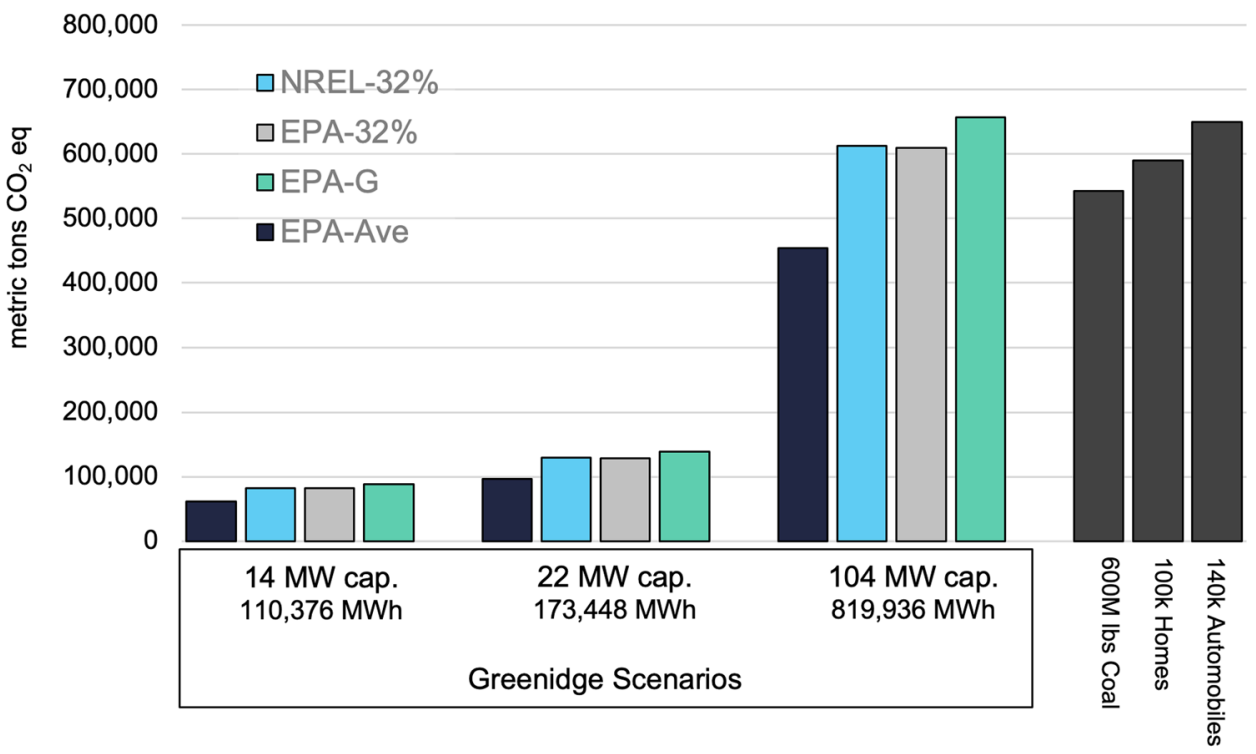

between the production of natural gas and ozone (Edwards et al. 2014; Kemball-Cook et al. 2010). For example, Edwards et al. (2014) observe ozone levels well above current air quality standards in oil- and gas-producing basins regions across the Western USA.

\subsection{Predictive model}

We estimate emissions of 138,977 $\mathrm{tCO}_{2}$-eq and 656,983 $\mathrm{tCO}_{2}$-eq for the 22-MW and 104-MW scenarios, respectively. Figure 3 compares these values to the emissions produced by burning 600 million pounds of coal, the annual emissions produced to power 100,000 homes, or the annual emissions of 140,000 passenger vehicles (EPA 2020).

\subsection{Consequential case}

The attributional and predictive models analyze the potential emissions from the Greenidge Power Plant. The consequential case considers the impact of expanding Bitcoin mining operations to other locations (Fig. 4). Results match expectations; for example, the type of plant makes a significant difference in estimated emissions, and the estimated emissions from using an inefficient steam turbine are $48.7 \%$ higher than emissions produced by using a more efficient CCGT. This further illustrates that the delta in emissions is proportional to the delta in plant efficiency. While the relative environmental impact associated with fuel production remains the same, the absolute impact of upstream
Fig. 4 Estimated emissions and emissions per MWh for the consequential cases

$$
\text { 1.E+06 }
$$

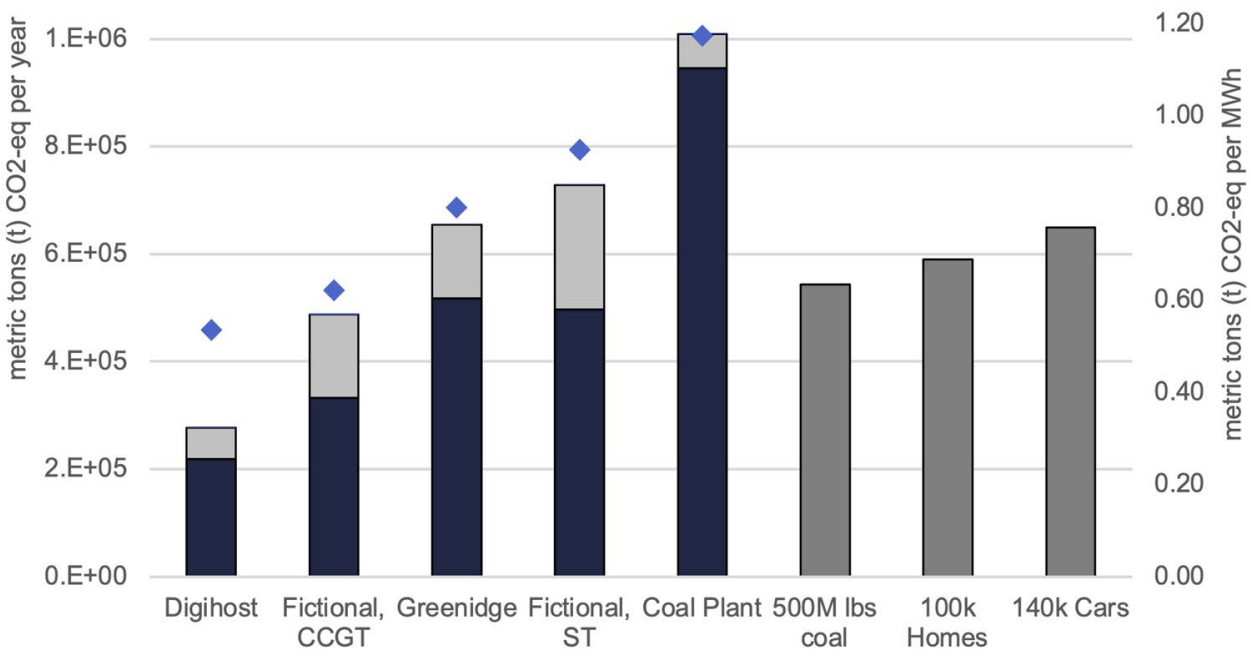

घElec. Generation

口Fuel Production 
processes also increases for inefficient power plants. Further matching expectations, we see that the Hardin Power Plant, which burns coal, has the greatest emissions rate, 1.16 metric tons ( $\mathrm{t}$ ) $\mathrm{CO}_{2}$-eq per $\mathrm{MWh}$, more than double the emissions rate estimated by studies mentioned previously in this paper. The vast proportion of emissions for this case are attributed to electricity generation (93\% of total emissions), while the proportion of emissions produced by fuel production is relatively low for this scenario $(6.3 \%$ of total emissions). In contrast, natural gas production contributes $21 \%$ for the scenarios based in NY, increasing to $32 \%$ for the scenarios based in Texas. This indicates that emissions from gas production are greater in the chosen Texas region, relative to NY. Overall, emissions are notable regardless of the scenario. In sum, the planned cases of Greenidge, Digihost, and Hardin would produce 1.9 million metric tons $\mathrm{CO}_{2}$-eq per annum. For comparison, New York's total emissions related to electricity generation amounted to 25.95 million tons $\mathrm{CO}_{2}$-eq in 2016 (NYSERDA 2021).

\section{Conclusion}

Our analysis used a transparent, replicable, and evidencebased Life Cycle Assessment to quantify the environmental footprint of behind-the-meter Bitcoin mining at the Greenidge Power Plant. At its initial level of operations, our model estimates annual greenhouse gas emissions of 88,440 t CO2-eq. If operations expand to $104 \mathrm{MW}$, our estimates increase to 656,983 t CO2-eq/yr. Emissions of this magnitude are comparable to the annual emissions of 140,000 passenger vehicles, or the emissions produced by burning 600 million pounds of coal. The plant-specific values that were used in this analysis include plant efficiency, the method of generation, the fossil fuel source, mining equipment, and control equipment. Our analysis shows that policy must not be aimed at limiting blockchain but should address the true source of the issue: energy-intensive cryptocurrencies and fossil-fuel generation. While this debate has primarily focused on GHG emissions, this analysis indicates that other pollution sources, specifically air pollution, are worth further examination in future case studies.

Bitcoin, the most prominent blockchain protocol, inherently values computing power and thereby energy intensity due to its proof-of-work (PoW) methodology. Unfortunately, many other cryptocurrencies are even less efficient than Bitcoin. In sum, these currencies consume disproportionate amounts of energy when comparing market capitalization and network power (Gallesdörfer et al. 2020). According to Gallesdörfer et al., other PoW protocols add $50 \%$ on top of Bitcoin's energy demand (2020). However, less energy-intensive methods of blockchain creation are in use today, including proof-of-stake (PoS) and proof-of-authority (Matthews 2019).
PoS eliminates the need for computing power by working on a validation basis. That is, instead of solving cryptographic puzzles, members validate transactions based on the stake they hold in the blockchain. Income is earned from transaction fees instead of from mining, in contrast to Bitcoin, where miners earn from both transaction fees and the actual mining of coins. Ethereum, the second largest cryptocurrency, started shifting towards this methodology in 2020 (Ethereum 2020). Alternatively, a shift towards lowcarbon methods of electricity generation could also limit the GHG impacts of blockchain. However, this transition is not straightforward. For example, generation sources such as solar PV and wind have significant land-use requirements (Miller et al. 2018). Using power density estimate from the same study (solar PV $=5.4 \mathrm{~W}_{\mathrm{e}} \mathrm{m}^{-2}$ (Miller et al. 2018)) would yield a land requirement of 4759 acres if Greenidge were to convert $104 \mathrm{MW}$ of generation to solar PV. Forcing miners to maintain a high renewable content or banning mining altogether could also drive miners into regions with more favorable climate policies, termed carbon leakage. A clear example of this can be seen as a result of China's regional cryptocurrency ban, which in turn has caused a massive influx of miners in North America (Dryden 2021). On a positive note, using renewables to power mining could generate significant new capital investment and career growth. For reference, wind turbine technicians and photovoltaic installers are currently two of the three fastest growing professions in the USA (U.S. Bureau of Labor Statistics 2020).

The availability of cheap and abundant natural gas has provided the northeastern USA with an alternative baseload source. There continues to be disagreement on the necessity of an underlying NG-based energy supply. This conversation is peripheral to our case study, which focuses on using a retrofitted, inefficient power plant to generate electricity for behind-the-meter uses at a time when New York State is pushing towards a carbon-free power grid by 2040 . At the same time, the plant is still permitted to produce $\sim 600,000$ $\mathrm{CO}_{2}$-eq/yr as of 2017 and 2018 (NYSDEC 2018; NYSDEC 2019). However, a significant proportion of emissions are produced in order to create a fundamentally different commodity - Bitcoin.

Greenidge is the first fossil-fueled power plant in the USA to mine Bitcoin behind the meter. As such, the plant is a disruptive player, demonstrating a lucrative business model to a massive industry. This shows that Greenidge is not an isolated instance, but merely the first of many players in a new market. Further potential cases could produce an estimated 1.9 million tons $\mathrm{tCO}_{2}$-eq per annum. Further, the environmental impact of this business model is not limited to individual sites but is spread out over upstream impacts as well. In combination, we see that behind-the-meter Bitcoin mining not only goes against local climate initiatives but also poses a significant danger to national initiatives due 
to feasible scalability, caused by an availability of existing infrastructure and favorable financials.

This study differs from previous studies by examining a discrete power plant and its disruptive business model. The power of this analysis lies in its clear and reproduceable framework, proving a framework for future analysis and decision-making as we address the severe socio-economic impacts of climate change.

Supplementary information The online version contains supplementary material available at https://doi.org/10.1007/s11367-022-02025-0.

Acknowledgements We would like to acknowledge Professor John Halfman, Department of Geoscience and Environmental Studies, Hobart and William Smith Colleges, for his contributions to this work.

Author contribution The manuscript was written through contributions of all authors. Data collection and analysis were performed by Martin Roeck. The first draft of the manuscript was written by Martin Roeck. Subsequent comments and edits were provided by Thomas Drennen and Martin Roeck. All authors read and approved the final manuscript.

Data availability All data generated or analyzed during this study are included in this published article (and its supplementary information files)

\section{Declarations}

Conflict of interest The authors declare no competing interests.

\section{References}

Anzalone R (2020) Bitcoin mining can be profitable, if you generate the power [Article] // Forbes. - August 13, 2020

Balasta S (2016) NRG adds nearly 2,800 MW of gas capacity by converting coal plants. Pennsylvania : SNL Energy Power Daily

Bare J (2011) TRACI 2.0: the tool for the reduction and assessment of chemical and other environmental impacts 2.0. Clean Techn Environ Policy 13:686-696. https://doi.org/10.1007/ s10098-010-0338-9

Belova A (2020) Shorter-cycle investments, shift to natural gas and adoption of new technologies to characterize oil and gas industry in 2020: Focus on Catalysts 2:10.1016

Bloomberg (2017) Coal is fueling Bitcoin's meteoric rise Bloomberg

Cambridge Center for Alternative Finance (2021) Cambridge Bitcoin electricity consumption index. October 24, 2021. https://www.cbeci.org/

Chang V et al (2020) How Blockchain can impact financial services - the overview, challenges and recommendations from expert interviewees. Technol Forecast Soc Chang 158. https://doi.org/10.1016/j.techfore. 2020.120166

Digicomist (2020) Bitcoin Energy Consumption Index. July 14, 2020. https://digiconomist.net/bitcoin-energy-consumption\#valid ation

Dryden J (2021) 'Up to 1 million' bitcoin processors could be relocated to Alberta from China under energy firm's proposal CBC. August 10,2021

Edwards PM et al (2014) High winter ozone pollution from carbonyl photolysis in an oil and gas basin. Nature Letter 514. https://doi.org/ 10.1038/nature13767
EIA Electricity Data Browser (2021). https://www.eia.gov/electricity/ data.php

EPA Environmental Protection Agency (2021) What is ozone? https:// www.epa.gov/ozone-pollution-and-your-patients-health/whatozone\#: : text=Stratospheric\% 20ozone\% 20is\% 20formed\% 20naturally,radiation\%20reaching\%20the\%20Earth's\%20surface

EPA (2020) Greenhouse Gas Equivalencies Calculator EPA. November 11, 2020. https://www.epa.gov/energy/greenhouse-gas-equivalenciescalculator

EPA (2020) Greenidge Generation LLC, monthly Electricity Data Browser. https://www.eia.gov/electricity/data/browser/\#/plant/2527? freq $=\mathrm{M} ;$ start $=201703$; end $=202003$; ctype $=$ linechart ;type $=$ pin; columnchart=ELEC.PLANT.GEN.2527-ALL-ALL.M;linechart= ELEC.PLANT.GEN.2527-ALL-ALL.M;pin=;maptype $=0$

EPA (2020) Inventory of U.S. greenhouse gas emissions and sicks: 1990-2018. - Washington D.C. United States Environmental Protection Agency, 2020

EPA (2021) Table 8.1. Average operating heat rate for selected energy sources Electricity Power Annual. https://www.eia.gov/electricity/ annual/html/epa_08_01.html

EPA WebFire Engine (2020) October 2020. https://cfpub.epa.gov/webfire/

Ethereum (2020) ethereum.org eth2. October 7, 2020. https://ethereum.org/ en/eth2/

Federal LCA Commons U.S. Life Cycle Inventory Database (2020). https://www.lcacommons.gov/lca-collaboration/search/ page $=1$;group $=$ National_Renewable_Energy_Laboratory

Feng Kushuang et al (2015) Drivers of the US $\mathrm{CO}_{2}$ emssions $1997-$ 2013. Nat Commun

Fichman B (2011) Annual Energy Review. Washington, D.C. : U.S. Energy Information Administration

Frankenfield J (2020) Cryptographic hash functions. Investopedia. February 4, 2020. https://www.investopedia.com/news/cryptographichash-functions/

Franklin Associates (2003) Data details for natural gas utility combustion

Franklin Associates (2017) Environmental life cycle assessment and cost analysis of Bath, NY wastewater treatment plant: potential upgrade implications. Washington D.C. : US EPA

Gallesdörfer Ulrich, Klaaßen Lena and Stoll Christian (2020) Energy consumption of cryptocurrencies beyond bitcoin. Joule Commentary. CellPress, September 16, 2020. 4:1839-1851. https://doi.org/ 10.1016/j.joule.2020.07.013

GE GE Power and Water (2015) 7HA.01/.02 Gas turbine. https://www. ge.com/content/dam/gepower-pgdp/global/en_US/documents/ product/gas\%20turbines/Fact\%20Sheet/7ha-fact-sheet-oct15.pdf

Greenidge Generation LLC (2020) Greenidge generation announces successful start of operations at 'state of the art' data center for digital currencies. Dresden March 5, 2020

Greenidge Generation LLC (2021) Greenidge generation announces comprehensive expansion plans. Dresden : Greenidge Generation LLC

Greenidge LLC (2021) Bitcoin Miner Greenidge Generation Holdings Inc. and Support.com, Inc. (Nasdaq: SPRT) Announce Merger Agreement Merger Announcement . March 22, 2021. https://ir. greenidge.com/node/6671/pdf

Greenidge LLC (2020) Greenidge Generation. About Greenidge Generation 2020. https://greenidgellc.com/company/about

IPCC Climate Change (2021) The Physical Science Basis; Summary for Policy Makers

Jiang M et al (2011) Life cycle greenhouse gas emissions of Marcellus shale gas. J Environ Res Lett 6. https://doi.org/10.1088/17489326/6/3/034014

Köhler S, Pizzol M (2019) Life cycle assesment of Bitcoin mining. Env Sci Tech 53:13598-13606. https://doi.org/10.1021/acs.est.9b05687

Köhler S, Pizzol M (2019) Supporting information: life cycle assesment of Bitcoin. Env Sci Tech. https://doi.org/10.1021/acs.est. $9 \mathrm{~b} 05687$ 
Kemball-Cook S et al (2010) Ozone impacts of natural gas development in the Haynesville Shale. Environ Sci Technol 44. https://doi.org/ 10.1021/es 1021137

Lei N, Masanet E, Koomey J (2021) Best practices for analyzing the direct energy use of blockchain technology systems: review and policy recommendations. Energ Policy. https://doi.org/10.1016/j. enpol.2021.112422

Li T, Castro PM, Lv Z (2017) Life cycle assessment and optimization of an iron making system with a combined cycle power plant: a case study from China. Clean Techn Environ Policy 19:11331145. https://doi.org/10.1007/s10098-016-1306-9

Li W et al (2016) Life cycle assessment of end-of-life vehicle recycling processes in China-take Corolla taxis for example. J Clean Prod 117:176-187. https://doi.org/10.1016/j.jclepro.2016.01.025

Littlefield $\mathbf{J}$ et al (2019) Life cycle analysis of natural gas extraction and power generation. Department of Energy/NETL. https://doi. org/10.2172/1529553

Liu Zhu et al (2020) Near-real-time monitoring of global $\mathrm{CO}_{2}$ emissions reveals the effects of the COVID-19 pandemic J Nature Commun Nat

Mackey TK et al (2019) 'Fit-for-purpose?' - challenges and open access opportunities for applications of blockchain technology in the future of healthcare. BMC Medicine. https://doi.org/10.1186/ s12916-019-1296-7

Matthews K (2019) 4 ways to counter blockchain's energy consumption pitfall GreenBiz

McCook H (2018) The cost and sustainability of Bitcoin

McKenzie J (2021) How Bitcoin mining keeps old fossil-fuel plant alive Mother Jones

Miller LM, Keith DW (2018) Observation-based solar and wind capacity factors and power densities. Environ Res Lett October 4, 2018. 10:13. https://doi.org/10.1088/1748-9326/aaf9cf

Mooney C, Mufson S (2018) Bitcoin's popularity has a downside: it's an energy glutton that could hurt Earth's climate, study finds Washington Post

Mora C et al (2018) Bitcoin emissions alone could push global warming above $2{ }^{\circ} \mathrm{C}$. J N Climate Change 8. https://doi.org/10.1038/ s41558-018-0321-8

Mutel C (2020) Main Page Brightway2. February 1, 2021. https://brightway. dev/

NASA (2019) GISS GISS Surface Temperature Analysis (v4). New York

National Fuel Empire Pipeline (2020) National Fuel. https://www.natfuel. com/empire/

NY Department of Environmental Conservation (2021) Reducing greenhouse gas emissions: limiting future impacts of climate change
NYS Department of Health (2008) Public health consultation: respiratory hospitalizations in areas surrounding the AES Greenidge power plant. Albany: New York State Department of Health

NYSDEC (2018) Permit Review Report, Greenidge, 2017. Avon, NY

NYSDEC (2019) Permit Review Report, Greenidge, 2018. Avon, NY

NYSERDA (2021) ny.gov New York State Regional Greenhouse Gas Inventory: 1990-2014 Report Fact Sheet. November 3, 2021. https://www.nyserda.ny.gov/-/media/Files/EDPPP/EnergyPrices/Energy-Statistics/greenhouse-gas-inventory-fact-sheet.pdf

OpenLCA Main Page (2020). February 1, 2021. https://www.openlca.org/

Pang Mingyue et al (2015) Environmental life cycle assessment of a small hydropower plant in China. Int J Life Cycle Assess 20:796806. https://doi.org/10.1007/s11367-015-0878-7

Plumer B (2019) As coal fades in the U.S., natural gas becomes the climate battleground. The New York Times. June 26, 2019

Redman J (2020) \$65M investment fuels natural gas provider's ‘behind-themeter' Bitcoin mining operation Bitcoin.com. March 2020

Shane Daniel (2017) Bitcoin boom may be a disaster for the environment CNN

Spegele Brian and Ostroff Caitlin (2020) Bitcoin miners are giving new life to old fossil-fuel power plants. Wall Street $\mathrm{J}$

Stephenson T, Valle JE, Riera-Palou X (2011) Modeling the relative GHG emissions of conventional and shale gas production. J Env Sci Tech 10757-10764. https://doi.org/10.1021/es2024115

Stoll C, Klaaßen L, Gallersdörfer U (2019) The carbon footprint of Bitcoin. Joule 7:3. https://doi.org/10.1016/j.joule.2019.05.012

Sun J, Yan J, Zhang K (2016) Blockchain-based sharing services: what blockchain technology can contribute to smart cities. Financial Innovation 2:26

U.S. Bureau of Labor Statistics (2020) Fastest growing occupations Occupational Outlook Handbook. October 7, 2020. https://www. bls.gov/ooh/fastest-growing.htm

Vries A (2021) de Bitcoin boom: what rising prices mean for the network's energy consumption Joule. 5:509-513

Yang Yi et al (2017) USEEIO: a new and transparent United States environmentally-extended input-output model. J Clean Prod 158. https:// doi.org/10.1016/j.jclepro.2017.04.150

Zhao Yan et al (2009) Life-cycle assessment of the municipal solid waste management system in Hangzhou, China (EASEWASTE). Waste Manag Res 4:27

Publisher's Note Springer Nature remains neutral with regard to jurisdictional claims in published maps and institutional affiliations. 